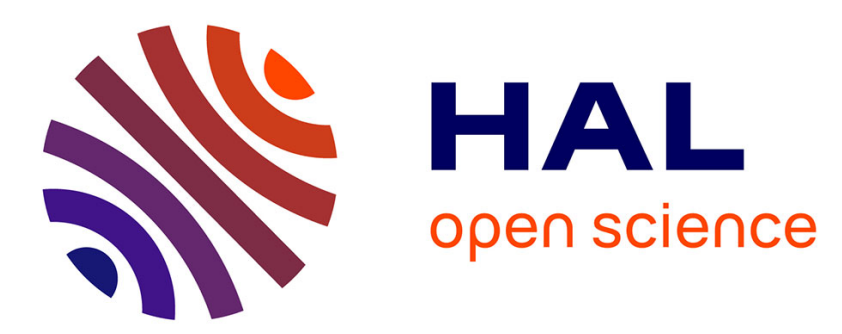

\title{
INTERACTIONS BETWEEN ELECTRIC MOBILITY AND PHOTOVOLTAIC GENERATION: A REVIEW
}

Quentin Hoarau, Yannick Perez

\section{To cite this version:}

Quentin Hoarau, Yannick Perez. INTERACTIONS BETWEEN ELECTRIC MOBILITY AND PHOTOVOLTAIC GENERATION: A REVIEW . 2018. hal-01713968

\author{
HAL Id: hal-01713968 \\ https://hal.science/hal-01713968
}

Preprint submitted on 21 Feb 2018

HAL is a multi-disciplinary open access archive for the deposit and dissemination of scientific research documents, whether they are published or not. The documents may come from teaching and research institutions in France or abroad, or from public or private research centers.
L'archive ouverte pluridisciplinaire HAL, est destinée au dépôt et à la diffusion de documents scientifiques de niveau recherche, publiés ou non, émanant des établissements d'enseignement et de recherche français ou étrangers, des laboratoires publics ou privés. 


\section{WORKING PAPER}

\section{INTERACTIONS BETWEEN ELECTRIC MOBILITY AND PHOTOVOLTAIC GENERATION: A REVIEW}

Quentin HOARAU ${ }^{1,2,3,{ }^{*}}$ et Yannick PEREZ ${ }^{1,4}$

Photovoltaic generation and electric mobility are both disruptive technologies in the power and transport sectors raising several issues regarding power grids. Precisely, questions about synergistic potentials when combining these two technologies have attracted academics' interest. Recent researches on this topic demonstrate that interactions between photovoltaic generation and electric mobility could decrease the overall burden on power grids, and empower one technology with the others specificities. Indeed, electric vehicles could use photovoltaic energy and benefit from a low-cost and carbon-free electricity to charge. In return, photovoltaic systems would use the bi-directional flexibility of electric vehicles battery to maximize their self-consumption. As these synergies operate, these technologies economic spillovers may improve, stimulating their joint deployment.

The objective of this paper is to develop a systematic framework in order to review the different under-lying conditions for synergy as they have been studied in the literature. It appears that this synergy was driven by technical characteristics as well as economic aspects. First, this synergy happens in middle-sized spatial configuration (large workplace buildings and charging station) and less obviously at other scales and in situation of technologically diversified system. Second, if it was poorly studied in the literature, the economic context (cooperation level between stakeholders, regulation and policies...) of interactions between photovoltaic generation and electric mobility is crucial for a successful synergy. Finally, we identify several remaining issues about these conditions that further researches could investigate.

\footnotetext{
${ }^{1}$ RITM, Université Paris-Sud, Faculté Jean Monnet, 54 Boulevard Desgranges, 92330 Sceaux, France.

${ }^{2}$ Climate Economics Chair, Palais Brongniart, 28 Place de la Bourse, 75002 Paris, France.

${ }^{3}$ Ecole Normale Supérieure Paris-Saclay, 61 Avenue du Président Wilson, 94235 Cachan, France.

4 LGI, CentraleSupélec, 92290 Châtenay-Malabry, France.

* Corresponding author. E-mail address: quentin.hoarau@chaireeconomieduclimat.org
}

\section{KEYWORDS}

\section{Electric Vehicle Photovoltaic energy Smart grid}




\section{Introduction}

Electric vehicles (EV) and photovoltaic generation (PV) 1 are two independent technologies disrupting their respective sectors. In 2017 for instance, world EV fleet has reached two million units, while solar energy has got the largest growth of all energy sources [1, 2]. Both technologies meet in power grids, in a distributed way, and tend to develop geographically close [3, 4. Many works have pointed out that the flexibility of EV battery would be an excellent complement for renewable energy integration [5. This potential synergy should provide individual and systemic benefits, by decreasing both technology costs and ecological footprints [6, 7, 8]. Eventually, it could even stimulate the development of each technology.

Nevertheless, several barriers exist for mutual beneficial interactions. EV and PV bring various technical and economic problems on power grids. These issues mainly result in additional costs on power grids managements, which increase with the penetration of each technology 9, 10. Moreover, a disorganized $\mathrm{EV} / \mathrm{PV}$ system can even reinforce these costs. Therefore, a growing literature has studied the combined integration of EV and PV (or other renewable energies) in power grids. Several authors have written reviews on the subject [11, 12, 13, 14 and have identified main technical features of such integration. Assessing properties of EV/PV systems is a complex task as they depend on various technical, meteorological, behavioral, economic and political parameters. Moreover, the benefits of EV/PV synergy are often mixed with other benefits belonging to one single technology (such as energy trading outside the system for instance). Therefore, the purpose of this paper is to build a systematic framework in order to assess EV/PV systems properties and the conditions for synergy.

This framework allowed us to identify the main conditions for synergy, that lead to better economic and technical efficiency and reduced ecological footprint of EV/PV systems. This synergy is determined by a smart control strategy aiming at optimizing the power flows in the system, mostly by adapting the EV charging to variations from photovoltaic generation. The spatial configuration of the EV/PV system is a major aspect of the synergy. EV/PV couplings were particularly efficient in intermediate scales (large workplace buildings and charging station). During the day, these configurations host a medium number of EV, which facilitates the predictability of charging demand. In addition, this demand is adapted to the PV generation profile and therefore, smart control is very efficient. On the other hand, the specificity of EV/PV couplings is less obvious on other scales (households, territories) and technologically diversified system. Generally, the literature did not assess the economic conditions of EV/PV synergy in a first intention. Nevertheless, we were able to identify the key-aspects of those conditions. First, it appears that the efficiency of most EV/PV systems was enforced by a certain level of cooperation between the different participants of the system. Cooperation is even more crucial as it is needed where the potential of EV/PV synergy is the highest. Then, that the interactions of EV/PV systems and power grids could lead to additional efficiency gains for the EV/PV system and for the different grids. Finally, the economic context (electricity pricing, entry barriers, support mechanisms) in which EV/PV systems were operating has a major role in the synergy.

The remainder of the paper begins by exhibiting the motivation and the components of our systematic framework. Then we detail the elements of our analytic framework with a third section exploring the different technical aspects, followed by a fourth section exploring the economic aspects of EV/PV systems. We will conclude the review by summarizing key-elements of EV/PV interactions and giving potential leads for future research.

\section{Description of the systematic framework}

Future smart grids will gather multiple technologies such as distributed generation, storage and flexible loads. Combining them optimally requires precise knowledge on the intricate interplays between technologies. Due to the vast diversity of possible systems and the numerous exogenous factors that influence the

\footnotetext{
${ }^{1}$ Abbreviations: EV, electric vehicle; PV, photovoltaics; ESS, electric storage system; PVCS, photovoltaic charging station; V2G, vehicle-to-grid; FIT, feed-in tariff; DSO, distribution system operator; TSO, transmission system operator
} 


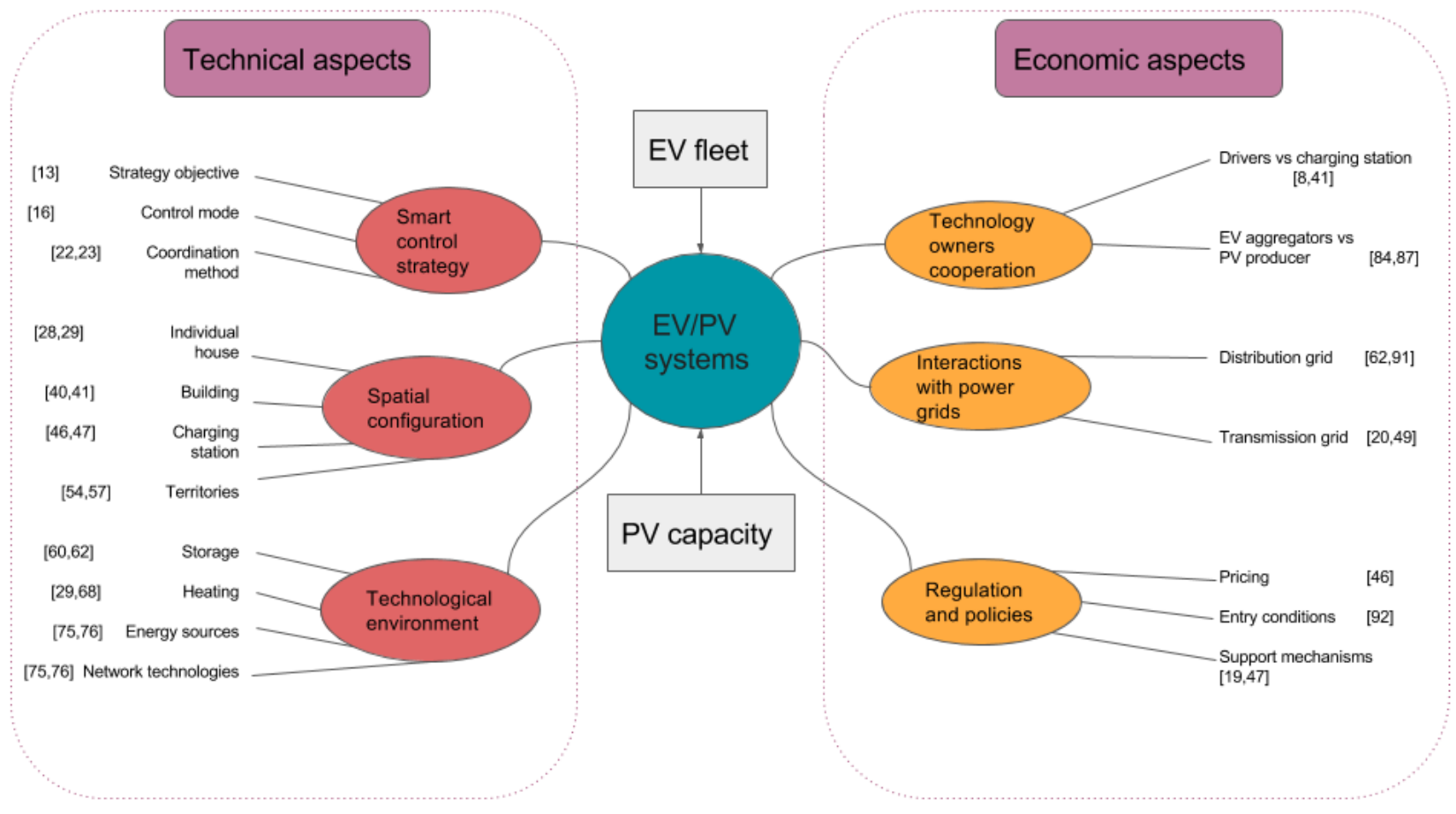

Figure 1: Our analytic framework of EV/PV interactions.

systems performances (meteorological, behavioral, technical economic and regulatory), assessing the complexity of such systems requires various analysis perspectives. Such perspectives could be focusing on a typical technology or on a typical configuration with multiple links between various technologies. We estimate that focusing on single links between two technologies (here EV and PV) is a relevant alternative perspective to contribute to the understanding on future power systems.

We designate by the artificial term "EV/PV systems" a technical entity that combines a specific quantity of electric vehicles and a capacity of photovoltaic generation. Through the literature we reviewed, it appeared that the constellation of EV/PV systems brings out several key-aspects influencing the potential for synergy between EV and PV. Figure 1 describes those aspects in detail. Those aspects can be divided in the technical aspects and the economic aspects. Technical aspects consist in a spatial configuration (house, building, charging station or territory) in a technological environment (storage, heat systems, additional energy sources or special network components). The performance of the EV/PV system relies on a smart control strategy that optimizes the charging (and discharging if V2G available) with PV generation and the various constraints of the spatial and technological environment. Beyond technical aspects, the EV/PV systems, as most future power systems, depends largely on economic and regulatory aspects. More precisely, we identified the main feature of the economic context as the emergence of cooperative behaviors inside $\mathrm{EV} / \mathrm{PV}$ systems, the interactions of the EV/PV systems with the power grids (distribution and transmission grids) and regulatory and policies (pricing, entry conditions and support mechanisms).

\section{Technical aspects of EV/PV synergy}

An EV/PV system is set in particular spatial configuration and technological environment. The spatial configuration designs the technical and organizational conditions where EV and PV technologies are meeting. The technological environment gathers the other main relevant technologies that coexist and interact with electric vehicles and photovoltaic capacities inside the spatial configuration. Finally, both technologies in 
their spatial and technological environment are combined with a smart control strategy. This section details these three components: smart control strategies, spatial configuration and technological environment.

\subsection{Smart control strategies for $E V / P V$ systems}

Smart control strategies are the core of EV/PV systems. They form the main lever which enforces a potential synergy. Up to now, such strategies have been the most investigated aspect of EV/PV couplings. In this section we review broadly the main characteristics of smart control strategies. These are the strategy objective and the coordination method (optimization, heuristic, hybrid) with their data requirement and control mode (centralized or decentralized). A key-element in these strategies is the ability of EVs to use bidirectional flow (from and to the power system), namely vehicle-to-grid (V2G)

\subsubsection{Strategy objective}

Defining a strategy objective is generally the first step of a smart strategy. 13 provides a review of electric vehicles and renewable energy couplings by strategy objective. Those can be distinguished by the quantity considered, whether it is monetary or physical. An objective is generally specific to a particular organization of agents, the spatial configuration where it operates, and the technical means of coordination it uses. A monetary objective can be increasing the revenues of an entity (e.g. a charging station), or decreasing the costs of total energy (e.g. for a building), electricity costs (e.g. for a charging station), costs of charging (e.g. for an EV driver), or costs of electricity generation (e.g. for a system planer). Alternative objective can be energy efficiency or ecological footprint. With energy efficiency, the objective can be the improvement of the system self-consumption, or the reduction of grid power imports, power losses in the system, or system total energy. The ecological footprint can be direct or indirect emissions of carbon dioxide or combination of pollutants. As we will see later, a smart strategy can also aim to combine several of these objectives.

\subsubsection{Control mode}

In smart grids, the control mode defines the level of coordination of flexible charges and in EV/PV systems almost exclusively EVs. This control can be either centralized or decentralized. A detailed introduction to these concepts is presented in [16]. In a centralized mode, a special agent (the so-called aggregator) manages the scheduling of the EV fleet charging. An aggregator can be the manager of an EV fleet, a charging station, a district microgrid. This mode is advantageous because it provides good results, with a good utilization of network capacities and ancillary services. Its drawbacks are that it requires a heavy communication architecture handling large amounts of data. In a decentralized mode, EV drivers organize their charging themselves by reacting to incentives of an aggregator. Examples of such aggregators include the ones for centralized control, but also larger actors as the distribution system operator (DSO). Typically, drivers are incentivized by dynamic electricity prices. Compared to the centralized control, it requires less complex communication systems and has a better consumer acceptance. On the other hand, its gains are lower and it requires a precise estimation of the user reaction to incentives.

\subsubsection{Coordination methods}

A coordination method is the mathematical formulation of the control strategy. It gathers together the strategy objective, the control modes with the diverse constraints on EV (charging demand needs, battery availability), PV generation, other technologies availability and other technical constraints (e.g. from power grids). We distinguish coordination between optimization methods, heuristic methods and hybrid methods.

\footnotetext{
${ }^{2}$ For more detailed information, a technical review of electric vehicle fleet management can be found in 15
} 
Optimization methods. One of the most common methods for energy management in EV/PV systems is to optimize an objective function (based on cost, energy efficiency or ecological footprint). Typically, this function can be the imported power from the grid (in cost or energy) over a given time. It can be also: power losses, system total lifetime cost, and direct and indirect pollutants emissions... This function can also be a combination of different objectives. As we will see later, multi-objective optimization methods are an adequate way to simulate cooperation between different actors.

As an illustration, we formulate a simple problem for a system with an independent load, several charging EVs and PV power. The system manager would want to minimize its grid power costs over a certain time under the following constraints: conservation between energy produced (PV and grid) and consumed (load, EVs and losses), EV charging dynamics, EV battery limits (minimal and maximal state of charge), power limits for charging, possibility of bidirectional EV flows (vehicle-to-grid) and the state of charge required by drivers. Such problem would require data on power grid prices, PV generation profiles, load profiles and charging efficiencies. Solving an optimization problem depends mostly on the functional forms. Linear, quadratic and more generally, most convex problems are easily manageable with numerical solvers. When functions are not convex, genetic algorithms and particle swarm optimization algorithms can achieve nearoptimal results in a reasonable computation time. As the problems contain several uncertainty sources (for solar irradiance, EV charging demand, electricity prices...), stochastic modeling can be used. An objective function would then be the expected value of the objective functions over different scenarios. Several authors have incorporated stochasticity in their smart strategies. [17] shows that a microgrid revenue of a difference between a strategy with perfect forecast and a stochastic optimized strategy to $1-9 \%$. In this case study, the range was comparable to improvement of a stochastic optimized strategy over the uncontrolled strategy. Similarly, [18 show that a stochastic algorithm decreases forecast error by 15-30\% compared to a deterministic algorithm. Finally it is possible to use statistical methods to get prediction of EV arrivals, PV power or grid electricity prices [19, 20].

Heuristic methods. Energy management systems of EV/PV systems often need simple logical rules to react instantaneously to new events (plugging/unplugging of an EV, decrease of PV power, electricity price). Ruled-based decision making provide a simple heuristic method to manage the system with little data requirements for prediction. Typical example of such method can be found in references [21, 22]. [22] shows that it can even provide results almost as good as optimization problems, while reducing the energy management system computation time by a factor 300 .

Hybrid methods. Optimization and heuristic can be combined as hybrid approaches. [23] define a smart control strategy by a two level approach. Before every day of service, an offline deterministic optimization gather data on EV charging needs, PV power and grid prices and a database of past optimal strategies. A second step is a real-time approach that uses a machine learning algorithm (based on the database of past events) and rule-based decision making. The authors demonstrate that such methods do not require any forecasts on PV power and charging demand while getting near-optimal strategies. The hybrid strategy of 24 consists in a dynamic price forecasting algorithm and a rule-based decision making algorithm.

\subsection{Spatial configuration of $E V / P V$ systems}

Smart control strategies are designed for particular spatial configurations where EV and PV technologies are gathered. These configurations bring specific constraints. We distinguish the following levels: individual house, commercial building and workplace, charging station, or territories. In addition to spatial level features, the number of EVs (or fleet size), the PV capacity and the aggregation level play an important role.

\subsubsection{Individual household}

The smallest scale for $\mathrm{EV} / \mathrm{PV}$ coupling to operate is in residential households. Several works have shown that $\mathrm{EV} / \mathrm{PV}$ coupling could improve utilization of those two technologies aiming at leading houses towards the objective of zero net emissions over a year. Typically, EV charging becomes less costly while solar panels self-consumption increases. 25] exhibits the conditions, based on a case study in Hawai, that 
would lead EV total ownership cost to be lower than their plug-in hybrid EV or internal combustion engine vehicle competitors. Integrating EV in an electricity mix with high penetration of PV leads to much more attractive EV. 26] studies the domestic EV charging in house equipped with solar panels. The authors find that the effectiveness is highly dependent on the driver's mobility uses. Indeed, a long-range commuter does not take advantage of PV charging while private users with several daily travels at home benefit of almost $70 \%$ of PV energy in their EV charging. Short distance commuters have around $40 \%$ of PV energy in their EV charging. Electricity bill savings are rather low (around 100e per year) for everyone. Two case studies carried for Sweden and UK, 27] and 28] are developing a Markov chains stochastic model of energy consumption of households equipped with PV systems and owner of EV using real data. Both studies show a poor EV/PV synergy. Indeed, most EVs come back home and plug in the evening during the household peak load. As the authors do not define a smart charging, EVs only increase energy consumption and its standard deviation. In both cases, they point out that EV disturbances on local grid (measured by consumption standard deviation) are attenuated at large scale by statistical effects. For a microgrid of a residential district (from one to a dozen buildings) equipped with solar panels of $10 \mathrm{kWp}$ each, 29. seeks to minimize total operational power cost. These costs gather EV charging, V2G use, other types of electric consumption and heating. By solving the linear programming problem, the authors find a 8-33\% cost reduction per building. Cooperation between buildings through direct power exchanges improves cost reductions. Moreover, V2G use allows an extension of self-consumption, but has a very limited effect on overall operational costs due to battery degradation costs.

30 formulates a mobility model (with Markov chains) and a predictive model for the house load and its PV electricity generation. The authors then develop a stochastic optimization model minimizing grid energy purchases. By considering respectively a Tesla S and a Nissan Leaf, annual cost reductions are - $493 \%$ and $-175 \%$. We will note that those tremendous falls are due to vehicle-to-grid utilization, with high feed-in tariffs and without taking into account potential cost on the battery. It is also important to note that optimal charging is little coordinated with the PV generation profile. 31] combines a mobility model and a building electric consumption model to simulate the energy management of a "zero energy building". The authors quantify the benefits of Vehicle-to-House $(\mathrm{V} 2 \mathrm{H})$ for tens houses with one EV each. The authors then determine the sensibility of their results to PV capacity $(20-90 \mathrm{kWp})$ to the degree of cooperation of $\mathrm{EV}$ owners (i.e. their chosen state-of-charge fraction available for $\mathrm{V} 2 \mathrm{H}$ ). Two scenarios are simulated, with and without electric storage system (ESS). Depending on the installed capacity, solar panels provide 20$30 \%$ of houses loads. And depending on the authorized state-of-charge fraction for V2H, EV can provide up to $30 \%$ of house power. ESS reduces even more grid power imports. 32 models the electric system of a residential household (consumption, PV generation, ESS and EV). Once consumption is optimized, a rule-based decision making algorithm is used to manage EV and battery storage charging in function of the PV generation and electricity time-of-use tariffs. The proposed algorithm leads to a $62 \%$ decrease on the electricity bill. The individual effect of EV on the total strategy efficiency is difficultly tractable compared the stand-alone battery one, but its role is even greater that its initial state of charge is high. 33] uses empirical data of residential consumption and PV generation to assess the effect of a combination of house loads, EV recharging and solar panels. Using a commercial energy management system, the authors find a $30-50 \%$ reduction on the electricity bill.

Having an EV almost double the electricity consumption of a household, so having an own energy source (as PV) makes sense. Nevertheless, it appears through the literature that a coupling of EV and PV inside households can be beneficial, but those benefits are bounded by the utilization of EV for mobility. Indeed, EV are usually away from home during the day and therefore cannot benefit from maximal generation of PV. As we will see later, additional energy flexibility source (as battery storage or thermal systems) is beneficial to the house energy management.

\subsubsection{Buildings}

In the case of individual houses, we saw that the benefits of EV/PV coupling could be limited by the absence of EV at maximal PV generation hours. EVs should be parked at this time, whether at workplaces or in other car parks. Given that those places should be able to host more EV, this would allow a better predictability, EV/PV coupling should be more efficient to improve self-consumption in commercial or 
workplace buildings. In a commercial building equipped with solar panels of $50 \mathrm{kWp}$ capacity, 34 seek to optimize the charging of $12 \mathrm{EV}$ by minimizing total electricity costs. EV mobility is modeled simply with arrivals and departures hours, and arrival states of charge as fixed parameters. Smart charging defined on PV power predictions allows to reduce electricity purchases from 6 to $15 \%$ compared to an uncontrolled charging. 19 formulates an optimization problem for the charging management of $6 \mathrm{EV}$ at a workplace equipped with $9 \mathrm{kWp}$ of PV capacity. Compared to an uncontrolled charge, optimized charging allows to improve self-consumption by 20-30\%, while generating profits. 35 tests different EV charging strategies on a large residential building. Depending on the number of EV parked, self-consumption can be improved by 20\%. [36] uses a linear programming algorithm to define EV smart charging on a microgrid of a residential neighborhood in a case study based on Dutch data. The microgrid has $31 \mathrm{kWp}$ PV capacity and 2-5 EV, which charging demand is estimated using probabilistic methods. The authors find an improvement of 13$38 \%$ of the microgrid self-consumption. 37 formulates an optimization problem to minimize the operational cost of an eco-district microgrid with EV and PV systems. Compared to an uncontrolled scenario, optimal management lowers operational costs by $70 \%$. For a university campus microgrid, 38, develops an energy management framework in two levels: the first one deals with energy exchanges with the grid while the second one coordinates EVs charging. Such system allows to reduce imported power by $73 \%$ and to improve selfconsumption by 50\%. 39] develops a simulation model of power management of a workplace. By comparing a "classical" system (with an classical vehicle, gas and electricity heating) with a "green" one (with an EV, PV system and heat pump), the authors find a $40 \%$ diminution of primary energy consumption and $40 \%$ diminution of $\mathrm{CO}_{2}$ emissions. 21] simulates the DC electric system of a building with $6 \mathrm{kWp}$ PV capacity and a parking hosting $8 \mathrm{EVs}$. Energy management follows a rule-based decision making algorithm allowing vehicle-to-grid. Compared to a dumb charging case, the smart charging leads to a decrease of $43 \%$ of charging costs. 40 assesses the economic feasibility of a workplace charging station with solar capacity. The authors use a stochastic dynamic optimization problem to define the smart charging EV that minimizes imported power from the grid. EV arrival and PV power are estimated using probabilistic methods. Compared to the uncontrolled charging with and without PV, smart charging with PV leads to a reduction of respectively 80 and $90 \%$ of imported power. Then, the authors develop an investment model to determine the pay-back time of the station depending on user tariff and regulatory tools. Two case studies are made in two US state with different solar irradiation and subsidy frameworks. The authors find that optimal charging matters when PV capacity is low. In [41], an interesting sensibility study is made on categories of buildings electric loads. Based on sixteen building categories (e.g. offices, hotels, hospital, schools...), the authors show that the smart control strategy of a EV/PV building system bring costs reductions from $4 \%$ to $18 \%$. Moreover, the coupling performance is highly dependent on the building type and its typical load profile. For instance warehouses, fast-food restaurants, hostels and supermarkets benefit the most of EV/PV synergy, contrary to hospitals and health care centers.

\subsubsection{Charging station}

This section focuses on the study of EV/PV complementarity in the case of charging stations with on-site photovoltaic capacities (noted hereafter PVCS) or off-site PV powerstation. Their purpose can be commercial or professional (e.g. included in workplace). The number of vehicles involved in PVCS management are diverse, since charging station goes from a small workplace station to groups of large car parks. 14 provides a review of PVCS main techno-economic features with its environmental benefits. In a Monte-Carlo simulation, 42] shows that the potential shares of PV energy in EV charging goes from 1\% to $72 \%$ without smart charging. Season and charging power are shown to be the main determinants of the efficiency of the PV-based charging. Indeed, lower power increases charging duration and so PV selfconsumption. 43 considers novel technology of solid-state transformers to enable a flexible management of a PVCS. The authors develop a rule-based decision making model in order to participate in ancillary services for the grid. In their case study of PVCS hosting $60 \mathrm{EVs}$ with a 200kWp PV capacities, the authors find an increase of $200 \%$ of revenues from ancillary services compared to their uncontrolled case without PV. 24. proposes an architecture for a PVCS with a hybrid control strategy. The authors' smart control strategy leads to a reduction of $50-75 \%$ charging costs, while increasing PV self-consumption by $20 \%$. The strategy does not particularly improve charging completion which stays stable at $85-92 \%$. [44 seeks to maximize 
profits of a PVCS investor while considering the grid constraints. By optimizing the net present value of the PVCS revenues and costs, the authors find that a smart charging of a fleet allows to increase owners' benefits by $10 \%$ while reducing $40 \%$ of the peak load. In their study of a small charging station equipped with up to $10 \mathrm{kWp}$ PV capacity for a single EV (Nissan Leaf or Tesla Roadster), 45] develops a technical model to introduce a smart strategy. Results show that vehicle-to-grid capabilities can be enhanced by $60 \%$ for ancillary services. For a PVCS able to host $300 \mathrm{EVs}$, [17] develops an operational framework in two steps to maximize the PVCS profits. A first stochastic algorithm calculates day-ahead grid power need and marginal electricity cost for the PVCS. A second one optimizes the charging scheduling of EV. This smart strategy increases revenues of the PVCS operator by 3\% in summer and 10\% in winter. 46. considers a charging station hosting until $650 \mathrm{EVs}$ and equipped with $100 \mathrm{kWp}$ of solar capacity. The EVs are divided in three categories that define their charging profile: commercial (night charging), commuter (long day charging) and opportunity (short day charging). The authors minimize the grid power purchases using different optimization algorithms (deterministic and stochastic). Compared to the uncontrolled strategy, the smart strategies double the PV utilization while reducing grid power costs by $86-95 \%$. 47 studies the technical and economic feasibility of a PVCS from an investor point of view. The authors investigate various designs of the PVCS management (control strategies, storage). From real parking data, the daily correlation between occupation profile and PV generation is found to be between $36 \%$ and $59 \%$. In every case, the PVCS is found to be profitable with a $7 \%$ interest rate on the period covering PV modules lifetime. [48, has been studying the management of an EV parking lot in ancillary markets (regulation and reserve). Revenues of the PVCS are defined by the addition of participation of EVs in various ancillary markets (energy, spinning reserve, regulation up and down) and the charging and parking fees of EVs. Costs gather the purchased power from the grid, penalties in markets, payment to EVs owners for their vehicle-to-grid services, and battery degradation costs. In one of their case study, the distribution system handle a $200 \mathrm{kWp}$ solar farm. In this situation, the authors find expected profits $5.3 \%$ higher than in the case without renewable energy. In this scenario, PV and EV systems interact indirectly in energy markets. Noticeably, regulations market revenues decrease $(-2.6 \%)$, while reserve revenues remain steady and energy market revenues increase $(+10 \%)$. 49. develops a management model in which the PVCS is able to use vehicle-to-grid capabilities, to trade energy and offer reserve services to the grid. The optimal strategy leads to a $250 \%$ decrease on the PVCS energy costs on average along the year.

\subsubsection{Territory}

In this section, we review articles dealing with EV/PV synergy at territory scale. This scale is much larger than the previous ones. It can be cities, regions, countries. Territories can host a large number of EV and high PV capacities. The power grids considered are large distribution grids and transmission grids.

The issue of coupling EV and PV matters to companies with substantial transport and electricity needs. [50, 51, 52] look at joint investments possibilities in EV and PV. For a Chinese taxi company, [52] uses an energy optimization model to assess the net present cost and carbon footprint of combinations of technologies (including grid and PV power, EV and battery storage). The authors find that grid-powered EV are the most economical option compared to PV powered EV but emit twice as much carbon. Nevertheless, high carbon taxes, higher feed-in tariffs and lower interest rates are as many parameters that can make PV powered EV more profitable. In every case, PV-grid power is always less costly than PV-battery power as the one power source, although it emits more than twice less $\mathrm{CO}_{2}$ than PV-grid power. 50 develops a detailed decision model to calculate the economic payoffs of investments in EV or/and PV technologies. Synergy between EV and PV is defined by the difference between net present value of optimal combination in PV and EV, with the sum of net present value of optimal investment in separated technologies. In the scope of managing a company fleet and electricity provision, the authors find a synergy of investment in $\mathrm{EV}$ or PV. The key parameter appears to be the grid electricity price. Indeed, EV/PV synergy only exists in a specific range of this price. Below the lower bound of grid price of this range, investing in EV only is more beneficial, while PV technology dominates above the upper bound. In a case study focused on Singapour, 53. models an aggregator controlling a large EV fleet (up to 600000 vehicles) recharge. The aggregator formulates a unit commitment problem in order to organize power generation of conventional plants with renewable energy sources and different ancillary services. EV charging is incorporated with 
different levels of complexity. If the authors conclude that smart charging only has marginal effects on overall mix $\mathrm{CO}_{2}$ emissions, they show that it is crucial to cover regulation power needed by strong PV capacities penetration. An increased $\mathrm{EV}$ share in the automobile fleet permits a larger penetration of $\mathrm{PV}$ energy. For EV owners, smart charging leads to a reduction of individual charging cost. Moreover, $\mathrm{CO}_{2}$ emissions decrease by $30 \%$. In the US context, 54 exhibits prospective load curves of a power system with a large penetration of plug-in hybrid EV (for now preferred to battery EV in the US) and PV capacities (up to $10 \%)$. Smart charging, synchronized with maximum PV generation times is evaluated by the peak load reduction and PV energy curtailment (due to over-generation). A $50 \%$ penetration of plug-in hybrid EV in the automobile fleet allows to reduce curtailments by $5-6 \%$ and a smart charging to extend this reduction by 1-2\%. 20] determines a collaborative strategy between PV energy producers and EV fleets. PV generation is scheduled in day-ahead with the system operator. The producer sends its generation prevision and is penalized depending on its error of predictions. Vehicle-to-grid support of EV allows producers to diminish their penalties. A particle-swarm optimization algorithm uses vehicle-to-grid capacity of an EV fleet to fill the gap between the scheduled PV power and the actual one. Over a year, the authors find a reduction of penalties by a factor from 2 to 10 for PV producers. Nevertheless, this strategy does not seem to bring any benefits to vehicle-to-grid participants, while they support for their own battery degradation. 6 seeks to maximize EV and PV penetration in a mid-sized city. Maximal penetration is defined by the distribution grid technical limits. The authors develop a control strategy in case study simulating a smart grid of midsize city. Compared to an uncontrolled charge, the authors find an increase of the maximal EV and PV penetration of $64 \%$ and $18 \%$. In this case, joint $\mathrm{CO}_{2}$ emissions from transport and power sector lower by $28 \%$. [55] investigates the large scale effects of $\mathrm{EV} / \mathrm{PV}$ couplings in households by extrapolating the results of a study of 51 Japanese households equipped with PV systems and EV. Based on a rule-based decision making algorithm including optimization tools the authors demonstrate a global cost decrease of $17 \%$ in the power system. [56] determines the effects of a large combined deployment of EV and PV (respectively up to 2M and $620 \mathrm{MWp}$ ) in a province of northern Italy. The authors consider three charging strategies (uncontrolled, controlled with and without vehicle-to-grid), and formulate a unit commitment problem in the new electric mix. The authors demonstrate beneficial effects in term of peak load and ramping reductions. [57 runs Monte-Carlo simulations to estimate the different determining characteristics of joint EV/PV development in Australia. Simulations use as inputs technology costs, fossil fuels prices and carbon price. The authors demonstrate that beyond a certain level of carbon tax (typically $50 \$ / t C$ ) and with high EV fleet size, PV become economically viable in the electricity mix. [58] studies the behavior of an aggregator in two ancillary markets (demand-side management and outage management). 15000 EVs and 140MWp PV capacity are included into a distribution system composed of variable weather-sensible zones. Demand-side management strategy is found to reduce $94 \%$ of customer costs increase induced by weather changes.

At large scales, EV fleet can also interact with other renewable energy sources such as wind power. As EVs and PV capacities are aggregated at high level, aggregators or virtual power plant managers could include these supplementary capacities. Multiple studies have investigated the possible synergies of wind power and electric vehicles [11, 12, 13. Hence EV/PV synergy seems then less specific at these scales.

\subsection{Technological environment of EV/PV systems}

Systems with combined electric mobility and photovoltaic generation could include additional technologies in the selected literature. These technologies were included in the system (e.g. heating system in buildings) or added to it (e.g. stand alone batteries). When taken into consideration in the system smart control strategy, these technologies show have a more or less essential role that is important to characterize in $\mathrm{EV} / \mathrm{PV}$ systems. In this section, we will review the effects of adding technologies in EV/PV systems. Technologies considered in the selected literature were: stand-alone battery electric storage system (ESS), Heat-ventilation-air-conditioning (HVAC) of buildings, other energy sources (wind power, combined heat and power units...) and innovative network technologies (DC systems, solid-state transformers, reactive power control). 


\subsubsection{Electric storage system}

Stand-alone battery electric storage system (ESS) is an obvious technology when it comes to variable distributed renewable sources. It allows a system equipped with variable energy capacities to increase its self-consumption. In the selected literature, EV/PV systems often incorporate a ESS as an additional flexibility source. We already pointed out that ESS can be beneficial in EV/PV systems especially when EV charging demand and PV generation profile were uncoordinated, or when EV demand were not flexible [59]. A few papers give us some insights on the actual added value of ESS in those systems.

[60] studies the influence of adding an ESS in a PVCS. The authors maximize PV self-consumption using an optimization algorithm. Among their results, they show that the ESS could increase charging completeness and decrease overall grid electricity exchange by a factor two. 61 builds a PVCS architecture from several modules estimating EV arrival and charging need and maximal PV capacity and chargers power respecting grid constraints. Then, the authors minimize the facility net investment costs. Operational functioning are designed to minimize power losses of the PVCS. One main result in the paper shows that an optimal charging station with battery storage reaches twice a better return on investment than a station only equipped with PV. In comparison with EV charging demand profiles of [62] for PVCS, the authors analyze the sensibility of their strategy performance to a $50 \%$ decrease ESS and PV costs. Results show that when EV charging demand is more desynchronized with the PV generation profile, ESS reduction costs appears to be more advantageous to the EV/PV system than PV costs reductions. 63 studies the influence of an ESS capacity on the performance of the smart control strategy of a building EV/PV system. The authors show that ESS efficiency is exponentially decreasing. $13 \%$ of the power grid reduction is achieved with ESS capacity of $10 \mathrm{kWh}$, while maximal reduction is about $25 \%$, reached with a $30 \mathrm{~kW}$ ESS. For a DC PVCS with stand-alone ESS, 64 co-optimizes charging costs and ESS use (i.e. number of discharging of ESS). The authors enlighten the trade-off between both objectives. Disregarding ESS use leads to a cost reduction of half while disregarding cost minimization lowers energy use in ESS up to 90\%. Already discussed earlier, the authors of [47] show in their study of a PVCS from an investor point of view, that due to its investment high costs, stationary storage led to profit loss of $58 \%$. Nevertheless, as the battery price should decline in the future, the authors find that delaying the ESS installation make it profitable.

\subsubsection{Heat-ventilation-air-conditioning systems}

Heating, ventilation and air-conditioning (HVAC) represent more than half of buildings energy consumption 65]. As a distributed energy resource, heat pumps are meant to play a role in smart grids [66]. Among other, their interaction with PV energy has been noticed because of the heat pump peak shaving potential 67. While studying EV/PV systems [29, 32, 39, 68, considered additional residential heat pumps as part of the smart energy management. In [32], the building energy performance is at first optimized, so the influence of its thermal system on the EV/PV smart strategy is not visible. Along with its smart control of households EVs, 29] utilizes an HVAC optimized management. By comparing to an uncontrolled case, the authors are reviewing the performance of their EV charging and HVAC management separately. HVAC optimal strategy only brings a reduction in yearly energy costs of 8-16\%, while smart EV charging only brings a $12-20 \%$ reduction. Then, joined HVAC and EV strategies reduce energy bill by 19-33\%. In this case, HVAC and EV charging have comparable benefits when controlled smartly. Moreover, their performance seems almost additive, showing that one management has little effect on the other. In 68, the authors have shown that a large penetration of EV could alleviate a high portion of PV curtailment. They simulate a similar scenario with as many heat pumps as EVs. Compared to the EV-only case, this new scenario shows that the heat pumps allow an additional reduction of curtailed PV energy. If the heat pumps impact is lower than PV, HP seasonal patterns are opposite to PV profiles with a higher use in winter for HP. This is why there is an interesting complementarity to be benefited for EV.

\subsubsection{Other energy sources}

We mentioned earlier that many efforts have been done in investigating the combination between EVs and RES in general. Especially, wind power interaction with EV has been widely investigated. Besides this, aspects of EV/PV systems studies also included micro-CHP (combined heat and power) generators or small fossil fuels generators. Micro-CHP units could show an interesting seasonal complementarity with PV 
energy. As CHP power depends on heat generation, its power is the highest in winter, contrary to PV power. 69] studies the energy management of a workplace equipped with PV and CHP units and an EV parking. It was not possible at first to discern respective effects of both technologies on the global system performance, because of the magnitude of the CHP power (one tenth of PV peak power) and its synchronization with PV power. Small dispatchable electric generators are included in 70 in their PVCS management study. They can provide the additional energy source, if the grid power price is high enough or in an islanded mode. Wind power, as the other major renewable source for electricity generation, is often considered with PV energy [11, 12, 13. Major differences with PV energy, are that the wind power peak is generally at night 71, and that it comes in large energy systems. Those systems have large flexibility needs and therefore only concerns large coordinated EV fleets. In those situations, EV fleet could charge with both PV (in day charging) and wind energy (night charging). 7. presents a comparison of charging strategy based on wind at night, and PV at mid-day. The authors develop an energy scenario for Portugal with among others, a large deployment of PV capacities, wind power and EV fleets. They point out that with an EV smart charging strategy, PV energy reduces curtailed renewable energy and $\mathrm{CO}_{2}$ emissions better than wind.

\subsubsection{Innovative network technologies}

Some innovative features regarding electrical network components can be incorporated in EV/PV systems. Those are: DC networks, solid-state transformers and reactive power exchange. While current power grids use almost exclusively AC current, low-voltage DC distribution grids are regarded as the appropriate framework for microgrids [2]. Such proposition seems justified because those systems will host mainly DC distributed energy resources (as PV panels, fuel cells, batteries...). EV batteries run on DC current and are therefore equipped with an AC/DC inverter that causes main charging/discharging losses [73]. DC systems should therefore be beneficial to EV/PV systems. 64, 74, 21] also studied EV/PV systems in DC networks, but no comparison were made with AC networks. 75 shows that for a small PVCS using a smart charging strategy, a DC system increases energy efficiency of EV charging from PV panels by 5\%. One could think that DC networks would particularly be useful in larger EV/PV systems, using vehicle-to-grid technology. 76] show that within a DC EV/PV system, revenues are increased by $0.5-1 \%$.

\section{Economic context of EV/PV systems}

In the literature describing technical features of EV/PV systems, economic aspects are mostly taken as fixed parameters (pricing, forecasting errors, drivers' behaviors...). This is consistent with the technoeconomic approaches used, but it misses several issues that seem crucial to characterize the whole potential of EV/PV synergy. First, the practical realization of such synergy remains tied by the willingness of several agents to cooperate, especially when EV/PV coordination comes at some cost. These costs include investments for hardware of the energy management system that enable smart control strategies, but also learning and transaction costs. Such requirements can be related to the well-known economic concept of the "energy efficiency gap", revealing that technical energy efficiency is prevented because of a series of non-technical barriers [77. Therefore the economic context of the development of such coupling should be analyzed carefully. Keeping this is mind, we reviewed again EV/PV systems literature through a prism of economic interactions and conditions (the second part of our systematic framework of Figure 1).

In this section, we will develop a review of mutual beneficial strategies in EV/PV systems and between $\mathrm{EV} / \mathrm{PV}$ systems and power grids (distribution and transmission). After this, we will discuss regulation and policy issues that promote EV/PV synergy. As the selected literature does not address these issues directly we will interpret them in order to answer those questions.

\subsection{Economic behaviors inside $E V / P V$ systems}

Several agents can share the ownership of a EV/PV system. Two possible cases of cooperation can be distinguished. First, when EV drivers interact with a charging station equipped with PV capacities (PVCS). Second, where an EV aggregator (e.g. company fleet manager or charging station manager) contracts with a PV energy producer. As we saw in the section on technical aspects, these EV/PV systems are located in 
intermediate spatial configuration (buildings and charging station), where the synergistic potential were the highest. How cooperation will happen at these levels is therefore crucial. After presenting how cooperation is described in the selected literature, we will review these two cases of cooperation.

\subsubsection{Cooperation in smart strategies}

To enable a smart control strategy, cooperation between participants in the EV/PV system is often required. We present the implicit methods introduced in smart control strategies that take such behaviors into account. First, we note that the issue of control mode has been widely studied in new energy systems with cooperative and non-cooperative game theory approaches [78, 79] and agent-based models [80]. Mainly studies involving distributed generation and storage have been studied in this literature, as in [81], and could be easily applied on EV/PV systems. When an EV/PV system control strategy uses such methods, it typically seeks to optimize its own objective function, along with the one of a another agent. Most common multi-objective method is the weighted-sum method. For instance, let's consider two agents in EV/PV systems with objective functions $X_{1}$ and $X_{2}$. Without cooperation, each agent define its strategy by maximizing (or minimizing) its own objective function independently from the other agent. With cooperation, agents agree to define their strategy by maximizing (or minimizing) $w_{1} X_{1}+w_{2} X_{2}$. As pointed out in [82, $w_{1}$ and $w_{2}$ can be interpreted as the preference of the decision maker towards the related objective. Alternatively, this method can be interpreted with game theoretical concepts. By posing $W_{i}=\frac{\alpha_{i}}{X_{i}}$, the latter problem can be considered as the linearized Nash bargaining solution in cooperative games theory. The following Nash bargaining problem would be to maximize $\left(X_{1}-X_{1}\right)^{\alpha_{1}}\left(X_{2}-X_{2}\right)^{\alpha_{2}}$ under both constraints of agents 1 and 2 . In this framework, $\alpha_{i}$ and $\underline{X_{i}}$ can be interpreted as the agents' bargaining power and non-cooperative payoff 83. Of course, weighted-sum method can be extended to multiple objectives without loss of generality. A Pareto frontier is the optimal solutions set defined by all the combination of $w_{i}$. An alternative method is the $\epsilon$-constraint multi-objective optimization, as used in [84. As its interpretation is less obvious in term of cooperation, and its use much less frequent than that of the weighted-sum method, we do not expand on this method. Cooperation between agents requires a value sharing scheme. This issue has been practically unaddressed in the selected literature. Only in [85], a Shapley value method is used in a cooperative game theory model to distribute the total benefits from the EV/PV synergy. More generally, the literature lacks analysis of business models.

\subsubsection{Cooperation between EV drivers and a photovoltaic charging station}

An issue raised by studies in the framework of PVCS is the cooperation between PVCS managers and EV drivers. Indeed, if uncontrolled strategies at least satisfy drivers' charging needs, efficient smart charging requires basic involvement from EV drivers, who should renounce some of their charging needs. A driver can be more or less flexible on his mobility needs, environmentally friendly or willing to participate in the power system stabilization 3 . Hence, charging station managers should give incentives to drivers to make a trade-off between their own needs and the PVCS needs. In the literature, no behavioral assumptions were made on $\mathrm{EV}$ drivers in term of reactions to incentives to cooperate in $\mathrm{EV} / \mathrm{PV}$ systems. Beyond the techno-economic nature of the selected literature, this point is yet largely unknown since no typical behavior of EV drivers has risen yet.

87 points out the importance of EV drivers preferences for their charging needs. From a PVCS investor's perspective, the authors simulate a smart control strategy in two scenarios where EV drivers are expecting from the PVCS to handle the totality or only half of their charging needs. The PVCS operates with a rulebased decision making algorithm which prioritizes vehicle recharge according to their parking duration and aim at maximizing their PV self-consumption. Results show that full charging service leads to operator's profits almost fifteen times higher than the case when drivers' demand is only half of their charging needs.

References [8, 23, 85] define several charging modes at different tariffs. For all of them, users who require charging should indicate a departure time to the PVCS. In 23, 85, there are two types of mode: premium and general. Premium mode offers maximum charging power at high tariff while general mode follows the

\footnotetext{
${ }^{3} \mathrm{On}$ the issue of willingness of of EV and PV users to create flexibility, 86 provides an interesting first study
} 
PVCS smart control strategy to define power delivered to the EV. [8] defines a more detailed business model. Three modes are proposed to users: premium, conservative and green. Premium mode offers maximal power at the highest price. Conservative mode offers charging at less cost, but not very different than premium. Green mode only ensures that the state of charge selected by the driver is reached at departure time. In the meantime, PVCS can freely organize the charging schedule of the green EV. In return, the offered tariff is $15 \%$ lower than the premium tariff. Green mode also allows PVCS to use vehicle-to-grid capacity of the vehicle as desired, in exchange for a remuneration for the EV owner (here at $85 \%$ of the green tariff). Green mode can be interpreted as a cooperative behavior from EV drivers. The only inconvenient for the Green driver is that if he decides to leave before his indicated departure time, his state of charge may even be lower than when he first plugged. Committing to the indicated departure time is therefore a form of additional cooperation with the PVCS. In the end, the authors' simulations show a cost reduction of around $48 \%$ for green users compared to premium and conservative users. For the PVCS, a 100\% proportion of green drivers leads to total operational cost reduction of $80 \%$.

38 . proposes an alternative way to promote cooperation drivers and the PVCS to maximize PV energy utilization. It defines a "solar-friendliness index" for each driver, that measures the correlation between the power consumed by the EV driver for charging and the PV generation profile. A queuing algorithm is then used to organize the charging of a set of EVs based on their solar-friendliness index.

As we discussed earlier, [40] addresses the issue of trade-offs between PVCS owner's revenues and EV drivers' costs of charging in the PVCS. Indeed, a PVCS owner has the dilemma of raising its parking fees to improve its profitability. On the other hand, EV owners would prefer charging at home or somewhere else if the parking fees are too high. The authors show by using a parametric analysis, that payback time appears to be concave with parking fees, meaning that marginal benefits of increasing the fees is decreasing. Compared to the charging costs of uncontrolled home charge at night, the authors are able to determine a maximal parking fee. [47] tests different customer tariffs for a PVCS. They show that a flat fee (e.g. monthly fee with unlimited free power for EV after) is much less profitable than a power-based fee.

As already discussed in 41, benefits of the defined collaborative strategy depended on building types. Moreover, the authors show that the driver's behavior has a major effect on the optimization of the building energy costs. Typically it is shown that long and diurnal availability of EV is not always a necessary condition for reaching best strategies. For instance a short duration availability is best fitted for a small hotel. In this case, total costs are reduced by $18 \%$ because of the smart control strategy. Moreover optimal energy needs for charging vary across building types from 20 to $70 \%$ of the state of charge of the vehicle.

Along with these papers, the literature on EV/PV interactions misses a proper realistic study on PVCS tariffs from both station manager and user's perspective.

\subsubsection{Cooperation between an EV aggregator and photovoltaic energy producer}

An EV aggregator manages the charging of an EV fleet. It can typically be a charging station manager, or a company fleet manager. It can contract with a PV energy producer to form a EV/PV system.

When it comes to design a coalition of cooperating agents, it is important to assess the optimal dimension of this coalition. [88] seeks to determine the best sizing possible of a EV/PV collaborative system. The system is defined by a coalition of an EV aggregator and a PV energy producer. They found that a $\mathrm{EV} / \mathrm{PV}$ system added value depends strongly on the ratio of the average aggregated vehicle capacity over the peak power of the PV energy producer. The authors determine a clear space of this ratio that makes the collaborative system globally profitable. Nevertheless, the length of this space is strongly dependent on the PV generation forecast.

85] studies cooperative game theory model where owners of charging station and PV capacities are different agents. In the non-cooperative case, PV producer sells its power to the grid, and the charging station buys power also from the grid. The authors then propose a cooperative scheme that brings the two entities in one coalition that maximizes the overall profits. Total profit is then shared according to the Shapley value method. Finally, cooperation raises total profits of $20 \%$.

[89] tackles the cooperation issues between a workplace building and a charging station. Building energy system includes solar panels, a fixed battery, workplace load and a heating system. Charging station is equipped with PV panels. The authors compare the cases without cooperation (separated optimization) and 
with cooperation. Without cooperation, both parties optimize their cost independently. With cooperation, the authors formulate a multi-optimization approach with a weighted-sum on each agent costs (as described in section 4.1.1 and exhibit the resulting Pareto frontier. The optimal weighting for the global system leads to a cost decrease of $22 \%$. It is interesting to note that global optimum is not the optimum for either agents. For the building owner, global optimum leads to $23 \%$ higher costs compared to its own optimum. At the same time, costs are $16 \%$ lower for the charging station at its own optimum compared to the global optimum. One will even note that building optimum leads the charging station to a worse outcome than in non-cooperative strategy. As stated in 4.1.1. weights can be linked to bargaining power in the negotiation, these results show the necessity of a fair sharing of cooperation benefits.

\subsection{Interactions between $E V / P V$ coupling and power grids}

In the previous section, we have reviewed collaborative schemes that would enable the EV/PV synergy. Nonetheless, EV and PV are constrained by their environment, i.e. distribution and transmission power grids. Integration of electric mobility in these grids has been widely studied in the literature [9, 16]. Benefits of collaboration between EV entities (driver, aggregator...) and grids have been demonstrated. In this section we address the issue of the integration of $\mathrm{EV} / \mathrm{PV}$ coupling in the power grids.

\subsubsection{Interaction with distribution grids}

The purpose of distribution systems is to bring electricity from transmission grid to end-users. Therefore, distribution system operators (DSO) design distribution grids and organize investments in grid reinforcements in order to optimize power distribution. Those heavy investments in equipment are made for several decades. Regulation is then designed to remunerate DSO according to its costs. As EV and PV units are generally directly connected to the distribution grid, the combined effects of EV and PV should be the most visible there. To study the impact of $\mathrm{EV} / \mathrm{PV}$ coupling, we start by reminding the individual effects of both technologies on the distribution grid and then analyze how beneficial the coupling could be to it.

[90] provides an overview of the technical and economic effects of distributed generation on the distribution grid. Technically, photovoltaic generation in distribution grids leads to trouble in grid operations (with congestion and over-voltage issues), difficulties in maintaining power quality (with increased harmonics) and in keeping power losses to low level (losses are proportional to power variations). For the DSO, this results in additional grid upgrading and missing revenues at short and medium terms. As [91] points out, any additional costs for the DSO leads to an increase of distribution fees. With current regulation, this leads to higher costs for non-PV users, while PV users do not participate fairly to their own impacts on the grid. Regarding EV impacts, technical issues are similar: more difficult grid operations (phase unbalances, overvoltage, congestion), worse power quality (harmonics) and higher power losses. The EV impact is strongly dependent on the charging power (from $3 \mathrm{~kW}$ at home to $50-150 \mathrm{~kW}$ with fast chargers) 9 .

As an effect of EV/PV synergy is to increase the system self-consumption and to reduce grid power imports, at first sight, wealth transfers should be reinforced. Nonetheless, EV charging could create an opposite effect. As EV raises substantially the owner's power consumption, DSO's revenues could be increased. These new revenues could balance the DSO's missing revenues due to PV self-consumption in the grid. To our knowledge, the resulting trade-off and the appropriate network tariff designs have not been investigated yet.

92 distinguishes EV services in distribution grids between load (congestion management and power loss reduction) and voltage services (magnitude regulation and unbalance reduction). A part of the EV/PV coupling literature deals with improving its integration in distribution grids by diminishing its stress on it. Although this literature is mainly technical, it underlines the beneficial effect of EV/PV coupling on distribution grids.

Controlling local peak load is a prime matter in order to stabilize the grid. Some the authors have studied local solutions to smooth load curves [93. Due to its high initial cost (millions of euros), transformer aging is an important feature to watch for DSOs. Congestion problems at transformer level (provoked either by PV or EV) tend to shorten its lifetime, which diminish the investment profitability. The authors of [94, 95, 96, 97. develop strategies for an EV/PV coupling to fulfill charging requirements and self-consumption with a 
softer impact on the transformer. 98. proposes a smart strategy based on technical constraints. It aims at smoothing EV/PV coupling stress to the distribution grid. A smart strategy manages EV charging such as PV and EV profiles are more synchronized which leads to a smooth transformer load curve. EV charging led by voltage can avoid overloads issues and ensure the charging of a larger number of EV. Smoothing the curve leads to lower power losses, as lesser high current and power variations happen.

A decentralized method of smart control strategies is to measure directly voltage profile of the system, in order to schedule EV to smooth it [99, 100. This results in lesser power losses in the grid [101. In the selected literature, [101] is one of the rare study to consider techno-economic aspects as exchanges of reactive power between EVs, PV systems and the distribution grid. The authors' method shows a $50 \%$ decrease in power losses in the grid, buy only in costs decrease of $3 \%$ for the EV/PV system. For instance, 101, 102 inject EV reactive power into the system, as it does not cause damage to the EV battery. As pointed out in [103], EV/PV system benefits towards distribution grid may have its limits. The authors provide a technical study of the effects EV/PV system on several aspects of power quality (voltages profiles and harmonics voltage distortions). They show that joint effect of PV and EV can reduce the load while improving voltage profiles on the grid, but does not really improve power quality (harmonics distortions).

For larger scales, references [58, 62 contain results that point out that a EV/PV synergy would be particularly beneficial in weak parts of the distribution grid. Those results indicate that EV/PV synergy could alleviate the distribution grid needs for reinforcements due to EV and PV. Nonetheless, this could require a specific contractual cooperation between the DSO and the EV/PV system manager. In their study on a PVCS system, 62 considers a grid in which grid strength (based on voltage magnitude) differs across areas. Results show that the influence of a smart strategy is even more beneficial in the weakest areas of the grid. Indeed, high power flows due to EV charging and PV power, and causes higher losses in a weak grid area and maximizing self-consumption in this area manages to improve the EV/PV system efficiency. This result is very intesting for the DSO, and hence could lead it to promote smart control strategy in $\mathrm{EV} / \mathrm{PV}$ systems. [58] studies coordinating strategies of EV and PV in a distribution system focusing on demand side management and outage management. The distribution system faces weather change and risk is diversely distributed in the fed zones of the grid. Demand-side management strategy appears to be more efficient in the riskiest part of the grid with costs reduction above $94 \%$. On the contrary, cost reductions in the safest parts of the grid are in the range 76-90\%. The authors of 47] show that allowing voltage support from the PVCS (with a regulation price of $25.6 € / \mathrm{MW} / \mathrm{h}$ ) increases PVCS profits by $27 \%$. As pointed out earlier, novel power grid components as solid-state transformers or DC microgrid are particularly adapted to $\mathrm{EV} / \mathrm{PV}$ systems. As they constitute an valuable solution for its distribution management, DSO could be tempted to install those technologies. This would indirectly create an incentive to exploit EV/PV synergy.

We can see through literature that a $\mathrm{EV} / \mathrm{PV}$ system can interact with the distribution in a mutually beneficial way. Technical advantages for the grid are obvious, but literature lacks a quantified study of these benefits. The recognition of this systemic benefits should influence the potential regulation for $\mathrm{EV} / \mathrm{PV}$ system in terms of entry conditions, pricing etc.

\subsubsection{Interaction with transmission grids}

EVs can provide services to the transmission system. Those would mainly be frequency regulation and peak load mitigation. Large penetration of intermittent and variable power as PV brings the opportunity to contribute for $\mathrm{EV}$ fleets to smooth the $\mathrm{PV}$ generation at large scale. The first issue is the control of the global load curve. In many regions, PV generation peaks during low demand periods and is low during high-demand periods. As PV capacity increases, this leads to high power ramps in mornings and evenings, namely the so-called duck-curve effect 104. In addition, a large penetration of commuter EV that charge during the evening should increase this effect. 54 studies a duck curve effect adding to a large EV fleet charging. The authors show that a smart charging displacing all EV loads from the global peak load, could diminish it up to $8 \%$ with $10 \% \mathrm{PV}$.

102 presents a method to design a cost-optimal planning locations and capacities of EV charging stations and PV plants in a territory. With a case study considering a transmission grid including 200000 EV charging in around 35 charging stations and $5 \mathrm{PV}$ plants with a total capacity $90 \mathrm{MWp}$, the authors show that PV energy manage to reduce the EV impact on the grid, and therefore allow substantial investments deferring. 
In 20, PV producers are penalized for their forecasting errors. Penalties are defined by the product of the real-time electricity price, the forecasting error and a penalty factor which varies between three deviation band errors. We already saw that the EV/PV coupling could reduce PV power imbalances by a factor 10 and penalties by a factor 15. Moreover, an interesting sensibility analysis is made over forecast accuracy. Transmission system operator would rather deal with participants with good prediction accuracy and low forecasting deviations. A smart strategy would erase total penalties in an even more efficient way when forecast error is low. Nonetheless, more money is saved when forecast error is high. Moreover, with uncontrolled strategy, cost total penalty over accumulated forecast error is not dependent on the accumulated forecast error. On tre contrary, with the smart strategy, it increases quickly. Therefore, once a smart control strategy is used, it is beneficial to aim the smallest forecast error. In [49, the authors compare the different effects of allowing a PVCS to trade energy, to offer reserve service, with an without V2G. They show that without V2G, they show that once offering reserve services, trading energy on the power market does not bring much advantage in comparison. On the other hand, trading is much more interesting once V2G is enabled.

Another issue to be investigated is the possibility of competition between the participation of EV in ancillary services and in the EV/PV synergy. Generally, frequency regulation is the most needed when the transmission system is facing sudden large variation as during the daily peak load. Our insight is that the correlation of the peak load with the PV generation peak is an important feature to estimate if EVs can participate in frequency regulation while profiting its synergy with PV energy. This case of conflict can be related to those identified in 105, between TSO and DSO services. On the other hand, frequency markets are likely to be quickly saturated as soon as there will be millions of potential EV participants. As PV stabilization needs will keep on increasing, this hypothetical competition issue may be irrelevant on the long run.

\subsection{Regulations and policies for efficient $E V / P V$ coupling}

In former sections, we showed that electric mobility and photovoltaic generation would have an interesting cooperation potential, and would able to reduce total costs of both technology, along with their respective ecological impact. Also, the $\mathrm{EV} / \mathrm{PV}$ coupling could even participate to the power system stabilization at distribution and transmission levels. In power systems, regulation and policies have a huge impact on technological development. For instance, recent studies are showing that regulatory and policy components have a prominent influence on distributed energy business models [106. It is therefore crucial to identify which regulatory and political tools and frameworks are appropriate in order to exploit efficiently potentialities of EV/PV coupling. To our knowledge, only [107] provides a framework to analyze policies in favor of solar-powered electric mobility. Such policies are not necessarily specific to EV/PV synergy, such as carbon taxes [57].

\subsubsection{Pricings}

It is generally accepted that dynamic pricing leads to a better economic efficiency, and particularly in demand response studies 108. Especially because they reflect a better reality of the different costs. In our literature, [76] provides a comparison of the efficiency of a EV/PV system with different tariff structure. The authors find that revenues of a $\mathrm{EV} / \mathrm{PV}$ system are increased by $0.5-1 \%$ with dynamic tariffs compared to flat tariffs, while power losses decrease by 10-20\%. 109. studies the effectiveness of different electricity pricing on the profitability of PV-ESS system for German households. First, the high price of electricity in Germany makes investments in self-consumption more profitable. Then, the authors study different network tariff designs, which account for $22 \%$ of the electricity price in Germany. Those tariffs are a reference volumetric tariff and the following alternative tariffs: a fixed charge, a maximum peak load tariff and a tariff combining the two previous tariffs. The authors find comparable decrease of the net present value of the installation for all alternative impact of the alternative tariffs compared to the volumetric tariff. Nevertheless, the decrease is lesser when there is a smart charging strategy for EVs. In addition, the authors determine that time-of-use tariffs does not significantly improve the performance of the EV smart control. 


\subsubsection{Entry conditions}

Regulation of the power system must adapt to facilitate new technologies diffusion (distributed renewable energies and information and communication technologies) [110. The design of those regulation reforms would have to embrace lots of elements, while being conceived dynamically. In EV/PV literature, regulatory is barely formally addressed, but some insights for appropriate regulation tools can be interpreted.

In the aforementioned literature, we saw that a new actor, the aggregator, was often invoked to manage jointly EV fleets charging and distributed photovoltaic generation. [111] defines the different types of aggregators in evolving power systems. The authors distinguish fundamental, transitory and opportunistic values of aggregation. A fundamental value lies in intrinsic economies of scale of the aggregator services. A transitory value is an aggregator service that could be potentially substituted by an appropriate regulation. An opportunistic value comes from inefficient or inappropriate regulation, and is more likely to disturb the power system rather than help it. EV/PV aggregators require a new regulation whether they would operate at the transmission level (frequency regulation...) or at the distribution level. Aggregated EV/PV systems in energy and ancillary markets require a novel regulation at transmission and distribution level, that should include all distributed energy resources. The entry conditions of such systems should be similar to the ones required by EV aggregators in order to participate in those markets. Frequency market is thought to be the most realistic market for EVs to participate 9. For many countries (France, USA), this would require a deep reform of energy markets design [112. Nonetheless, allowing EV aggregators to contract with a PV powerstation to lower its forecast errors could be an alternative and/or complementary solution as EV participation in ancillary markets.

We saw that EV/PV coupling could be particularly beneficial for the distribution system and its operator. $\mathrm{EV} / \mathrm{PV}$ systems in households, buildings and charging station should have entry issues as the site manager is in charge of the power system of the spatial configuration. For larger configuration, there is not yet any framework enabling DSO to contract flexibility services [9. A recent work (92]) proposes a regulation framework and road-map for EV integration in distribution systems.

\subsubsection{Support mechanisms}

Feed-in tariffs and other subsidies are commonly used by governments to stimulate PV technology development while EV is also heavily subsidized in many countries.

By taking different levels of FITs, [19] shows that the lower the FIT is, the more efficient the EV/PV coupling will be. Indeed, high FITs incentivize PV capacity owners to sell their whole production to the grid instead of cooperating with an EV fleet, that have to charge only using the grid. [113] shows that low FIT make profitable investments on both PV and EV compared to PV and classical vehicles.

In a Belgium context, 51 uses a multi-objective framework (investment costs and ecological footprint under the constraints of transport and power needs) to design company transport fleet and power system. The authors exhibit the Pareto of technology combinations investment in function of life-cycle $\mathrm{CO}_{2}$ emissions and either initial required investments (bounded rationality) or life-cycle economic cost (complete rationality). Without subsidy, the authors show a clear trade-off between economical (classical vehicle and grid electricity) and ecological (EV and PV electricity) options. Applying the actual governmental subsidies on both PV and EV make the EV/PV coupling the economic optimum as well as ecological for an investor with complete rationality. Nonetheless, if the investor has a bounded rationality, the latter result is less clear. In a similar way, [47] studies the influence of investment subsidies on the payback time of a PVCS. Payback time decreases linearly with the level of subsidy, from 14 years without subsidy to 6 years with a $50 \%$ investment subsidy.

Synergy between EV and PV raises an issue on the efficiency of public policy. In many countries, both technologies are subsidized, while the synergy between them is not considered in the policy. Thus the efficiency of combined separated subsidy policies seems questionable, especially since these technologies are more and more likely to be acquired jointly, as pointed out in [3]. Therefore, it is also possible that subsiding features of the EV/PV synergy, as PVCS, smart buildings, or energy management systems, would be particularly efficient for both EV and PV development. To our opinion, this issue deserves a more detailed investigation. 


\section{Conclusion and recommendations}

The forthcoming energy transition should bring complex technological systems in which each technology development will be closely linked together. The nature of these interactions and the understanding of their technical and economic determinants shall influence the pace of the transition towards more sustainable industrial systems. This paper focuses on one of these links between two apparently independent technologies: the potential synergy between electric mobility and photovoltaic generation. Based on a thorough literature review, we presented a precise description of EV/PV systems.

We showed how one technology could benefit from the other. This synergy has been analyzed in a framework distinguishing EV/PV systems in three components: its smart control strategy, its spatial configuration and its technological environment. From our point of view, it is difficult to determine on general effect of EV/PV synergy on both technologies lifetime costs due to the variety of the different influencing parameters. A specific study should then be conducted.

Then, we investigated the economic context of such synergy. Although the literature that we reviewed was mainly technical, we exhibited some elements on how EV/PV synergy was reinforced by cooperation between technology owners inside EV/PV systems, mutually beneficial interactions between EV/PV systems and power grids (transmission and distribution) and appropriate regulations and policy.

Our systematic framework allowed us to explore deeply the main aspects of the constellation of EV/PV couplings. In particular, such framework helped us to address economic issues that were poorly studied in the literature. In our opinion, such tool can be useful to analyze other systems where several technologies meet. For instance, it would be possible to apply this framework to the gathering of power generation technologies and heat systems (e.g. PV and combined heat and power) or other transport systems (e.g. biogas or hydrogen powered vehicles). In addition to the technical aspects and the economic context of a system, this framework could include social acceptance as a third aspect as this topic is crucial in smart grids 114 .

This review led us to enlighten unanswered questions worth, according to us, further investigation. First, the litterature we reviewed is not able to indicate a realistic typical decrease for EV on its lifetime costs in a territory covered by EV/PV systems. Then, the issue of cooperation between stakeholders taking place in $\mathrm{EV} / \mathrm{PV}$ systems still needs clarifications. In particular, the various behaviors of participants that would enable EV/PV synergy (transaction costs, reaction to pricing incentives...) require a precise study. Along with this, the sharing of the added value of the synergy between system participants remain a key issue. Practically, this requires knowledge on the appropriate business models that would be best suited for the car industry to give incentives to car owners to adopt smart charging. According to us, an efficient $\mathrm{EV} / \mathrm{PV}$ synergy requires certain levels of EV and PV in the system. Therefore, the efficient EV fleets and PV capacities developments in order to benefit from EV/PV synergies in a particular territory should be investigated. Also, the combined effect of EV and PV integration in distribution grid on the operator's revenue seems a crucial issue that should be investigated. The natural extension of such question would be to determine which tariff design would be appropriate for a distribution system with joint EV and PV systems. Finally, as both electric mobility and photovoltaic generation are subsidized separately, there may be a public policy taking into account the synergy that would be more efficient. Then, a practical regulation that would target specifically the synergy should be defined.

\section{Acknowledgment}

Special thanks to Anna Creti, Patrick Jochem, Jacques Percebois, Kristine Dreuilhe and Antoine Recanati for their useful comments.

\section{References}

[1] Global ev outlook 2017, two million and counting, International Energy Agency. Paris, France (2017).

[2] World energy outlook 2017, International Energy Agency. Paris, France (2017).

[3] M. A. Delmas, M. E. Kahn, S. L. Locke, The private and social consequences of purchasing an electric vehicle and solar panels: Evidence from california, Research in Economics 71 (2017) 225-235. 
[4] X. Li, P. Chen, X. Wang, Impacts of renewables and socioeconomic factors on electric vehicle demands-panel data studies across 14 countries, Energy Policy 109 (2017) 473-478.

[5] W. Kempton, J. Tomić, Vehicle-to-grid power implementation: From stabilizing the grid to supporting large-scale renewable energy, Journal of power sources 144 (2005) 280-294.

[6] A. Chaouachi, E. Bompard, G. Fulli, M. Masera, M. De Gennaro, E. Paffumi, Assessment framework for ev and pv synergies in emerging distribution systems, Renewable and Sustainable Energy Reviews 55 (2016) 719-728.

[7] P. Nunes, T. Farias, M. C. Brito, Day charging electric vehicles with excess solar electricity for a sustainable energy system, Energy 80 (2015) 263-274.

[8] W. Tushar, C. Yuen, S. Huang, D. B. Smith, H. V. Poor, Cost minimization of charging stations with photovoltaics: An approach with ev classification, IEEE Transactions on Intelligent Transportation Systems 17 (2016) $156-169$.

[9] P. Codani, Integration des véhicules électriques dans les réseaux électriques: Modèles daffaire et contraintes techniques pour constructeurs automobiles, Ph.D. thesis, Université Paris-Saclay, 2016.

[10] E. Baker, M. Fowlie, D. Lemoine, S. S. Reynolds, The economics of solar electricity (2013).

[11] D. B. Richardson, Electric vehicles and the electric grid: A review of modeling approaches, impacts, and renewable energy integration, Renewable and Sustainable Energy Reviews 19 (2013) 247-254.

[12] F. Mwasilu, J. J. Justo, E.-K. Kim, T. D. Do, J.-W. Jung, Electric vehicles and smart grid interaction: A review on vehicle to grid and renewable energy sources integration, Renewable and Sustainable Energy Reviews 34 (2014) $501-516$.

[13] L. Liu, F. Kong, X. Liu, Y. Peng, Q. Wang, A review on electric vehicles interacting with renewable energy in smart grid, Renewable and Sustainable Energy Reviews 51 (2015) 648-661.

[14] P. Nunes, R. Figueiredo, M. C. Brito, The use of parking lots to solar-charge electric vehicles, Renewable and Sustainable Energy Reviews 66 (2016) 679-693.

[15] J. Hu, H. Morais, T. Sousa, M. Lind, Electric vehicle fleet management in smart grids: A review of services, optimization and control aspects, Renewable and Sustainable Energy Reviews 56 (2016) 1207-1226.

[16] J. García Villalobos, Optimized charging control method for plug-in electric vehicles in lv distribution networks (2016).

[17] Y. Guo, J. Xiong, S. Xu, W. Su, Two-stage economic operation of microgrid-like electric vehicle parking deck, IEEE Transactions on Smart Grid 7 (2016) 1703-1712.

[18] E. Karan, S. Asadi, L. Ntaimo, A stochastic optimization approach to reduce greenhouse gas emissions from buildings and transportation, Energy 106 (2016) 367-377.

[19] D. van der Meer, G. R. C. Mouli, G. Morales-Espana, L. R. Elizondo, P. Bauer, Energy management system with pv power forecast to optimally charge evs at the workplace, IEEE Transactions on Industrial Informatics (2016).

[20] M. Ghofrani, A. Arabali, M. Ghayekhloo, Optimal charging/discharging of grid-enabled electric vehicles for predictability enhancement of pv generation, Electric Power Systems Research 117 (2014) 134-142.

[21] G. Byeon, T. Yoon, S. Oh, G. Jang, Energy management strategy of the dc distribution system in buildings using the ev service model, IEEE Transactions on Power Electronics 28 (2013) 1544-1554.

[22] N. Liu, Q. Chen, J. Liu, X. Lu, P. Li, J. Lei, J. Zhang, A heuristic operation strategy for commercial building microgrids containing evs and pv system, IEEE Transactions on Industrial Electronics 62 (2015) 2560-2570.

[23] N. Liu, F. Zou, L. Wang, C. Wang, Z. Chen, Q. Chen, Online energy management of pv-assisted charging station under time-of-use pricing, Electric Power Systems Research 137 (2016) 76-85.

[24] Q. Chen, F. Wang, B.-M. Hodge, J. Zhang, Z. Li, M. Shafie-khah, J. P. Catalao, Dynamic price vector formation model based automatic demand response strategy for pv-assisted ev charging station, IEEE Transactions on Smart Grid (2017).

[25] M. Coffman, P. Bernstein, S. Wee, Integrating electric vehicles and residential solar pv, Transport Policy 53 (2017) 30-38.

[26] L.-M. Ritte, S. Mischinger, K. Strunz, J. Eckstein, Modeling photovoltaic optimized charging of electric vehicles, in: Innovative Smart Grid Technologies (ISGT Europe), 2012 3rd IEEE PES International Conference and Exhibition on, IEEE, 2012, pp. 1-8.

[27] J. Munkhammar, P. Grahn, J. Widén, Quantifying self-consumption of on-site photovoltaic power generation in households with electric vehicle home charging, Solar Energy 97 (2013) 208-216.

[28] J. Munkhammar, J. D. Bishop, J. J. Sarralde, W. Tian, R. Choudhary, Household electricity use, electric vehicle homecharging and distributed photovoltaic power production in the city of westminster, Energy and Buildings 86 (2015) 439-448.

[29] J. Salpakari, T. Rasku, J. Lindgren, P. D. Lund, Flexibility of electric vehicles and space heating in net zero energy houses: an optimal control model with thermal dynamics and battery degradation, Applied Energy 190 (2017) 800-812.

[30] X. Wu, X. Hu, S. Moura, X. Yin, V. Pickert, Stochastic control of smart home energy management with plug-in electric vehicle battery energy storage and photovoltaic array, Journal of Power Sources 333 (2016) 203-212.

[31] E. Ancillotti, R. Bruno, E. Crisostomi, M. Tucci, Using electric vehicles to improve building energy sustainability, in: Electric Vehicle Conference (IEVC), 2014 IEEE International, IEEE, 2014, pp. 1-7.

[32] M. Alirezaei, M. Noori, O. Tatari, Getting to net zero energy building: Investigating the role of vehicle to home technology, Energy and Buildings 130 (2016) 465-476.

[33] A. Bedir, B. Ozpineci, J. Christian, The impact of plug-in hybrid electric vehicle interaction with energy storage and solar panels on the grid for a zero energy house, in: Transmission and Distribution Conference and Exposition, 2010 IEEE PES, IEEE, 2010, pp. 1-6.

[34] Y.-M. Wi, J.-U. Lee, S.-K. Joo, Electric vehicle charging method for smart homes/buildings with a photovoltaic system, IEEE Transactions on Consumer Electronics 59 (2013) 323-328.

[35] J. Van Roy, N. Leemput, F. Geth, R. Salenbien, J. Buscher, J. Driesen, Apartment building electricity system impact of operational electric vehicle charging strategies, IEEE Transactions on Sustainable Energy 5 (2014) $264-272$. 
[36] M. van der Kam, W. van Sark, Smart charging of electric vehicles with photovoltaic power and vehicle-to-grid technology in a microgrid; a case study, Applied Energy 152 (2015) 20-30.

[37] J. Soares, M. Silva, B. Canizes, Z. Vale, Microgrid der control including evs in a residential area, in: PowerTech, 2015 IEEE Eindhoven, IEEE, 2015, pp. 1-6.

[38] T. Zhang, C.-C. Chu, R. Gadh, A two-tier energy management system for smart electric vehicle charging in ucla: A solar-to-vehicle (s2v) case study, in: Innovative Smart Grid Technologies-Asia (ISGT-Asia), 2016 IEEE, IEEE, 2016, pp. $288-293$.

[39] C. Roselli, M. Sasso, Integration between electric vehicle charging and pv system to increase self-consumption of an office application, Energy Conversion and Management 130 (2016) 130-140.

[40] P. J. Tulpule, V. Marano, S. Yurkovich, G. Rizzoni, Economic and environmental impacts of a pv powered workplace parking garage charging station, Applied Energy 108 (2013) 323-332.

[41] Y. Kuang, Y. Chen, M. Hu, D. Yang, Influence analysis of driver behavior and building category on economic performance of electric vehicle to grid and building integration, Applied Energy (2017).

[42] M. Brenna, A. Dolara, F. Foiadelli, S. Leva, M. Longo, Urban scale photovoltaic charging stations for electric vehicles, IEEE Transactions on Sustainable Energy 5 (2014) 1234-1241.

[43] Q. Chen, N. Liu, C. Hu, L. Wang, J. Zhang, Autonomous energy management strategy for solid-state transformer to integrate pv-assisted ev charging station participating in ancillary service, IEEE Transactions on Industrial Informatics 13 (2017) 258-269.

[44] A. Awad, M. Shaaban, E.-F. Tarek, E. El-Saadany, M. Salama, Optimal resource allocation and charging prices for benefit maximization in smart pev-parking lots, IEEE Transactions on Sustainable Energy (2016).

[45] U. C. Chukwu, S. M. Mahajan, V2g parking lot with pv rooftop for capacity enhancement of a distribution system, IEEE Transactions on Sustainable Energy 5 (2014) 119-127.

[46] K. Seddig, P. Jochem, W. Fichtner, Integrating renewable energy sources by electric vehicle fleets under uncertainty, Energy (2017).

[47] R. Figueiredo, P. Nunes, M. C. Brito, The feasibility of solar parking lots for electric vehicles, Energy 140 (2017) 1182-1197.

[48] F. A. Gil, M. Shafie-khah, A. W. Bizuayehu, J. P. Catalão, Impacts of different renewable energy resources on optimal behavior of plug-in electric vehicle parking lots in energy and ancillary services markets, in: PowerTech, 2015 IEEE Eindhoven, IEEE, 2015, pp. 1-6.

[49] G. R. C. Mouli, M. Kefayati, R. Baldick, P. Bauer, Integrated pv charging of ev fleet based on energy prices, v2g and offer of reserves, IEEE Transactions on Smart Grid (2017).

[50] E. De Schepper, S. Van Passel, S. Lizin, Economic benefits of combining clean energy technologies: the case of solar photovoltaics and battery electric vehicles, International Journal of Energy Research 39 (2015) 1109-1119.

[51] E. De Schepper, S. Van Passel, S. Lizin, T. Vincent, B. Martin, X. Gandibleux, Economic and environmental multiobjective optimisation to evaluate the impact of belgian policy on solar power and electric vehicles, Journal of Environmental Economics and Policy 5 (2015) 1-27.

[52] J. Tang, B. Ye, Q. Lu, D. Wang, J. Li, Economic analysis of photovoltaic electricity supply for an electric vehicle fleet in shenzhen, china, International Journal of Sustainable Transportation 8 (2014) $202-224$.

[53] M. Huber, A. Trippe, P. Kuhn, T. Hamacher, Effects of large scale ev and pv integration on power supply systems in the context of singapore, in: Innovative Smart Grid Technologies (ISGT Europe), 2012 3rd IEEE PES International Conference and Exhibition on, IEEE, 2012, pp. 1-8.

[54] P. Denholm, M. Kuss, R. M. Margolis, Co-benefits of large scale plug-in hybrid electric vehicle and solar pv deployment, Journal of Power Sources 236 (2013) 350-356.

[55] M. Aachiq, J. G. D. S. F. Junior, T. Oozeki, Y. Iwafune, Evaluation of residential pv-ev system for supply and demand balance of power system, Electrical Engineering in Japan 195 (2016) 11-20.

[56] F. Fattori, N. Anglani, G. Muliere, Combining photovoltaic energy with electric vehicles, smart charging and vehicle-togrid, Solar Energy 110 (2014) 438-451.

[57] P. Vithayasrichareon, G. Mills, I. F. MacGill, Impact of electric vehicles and solar pv on future generation portfolio investment, IEEE Transactions on Sustainable Energy 6 (2015) 899-908.

[58] Q. Yan, B. Zhang, M. Kezunovic, The demand response support under weather impacts using pv generation and ev energy storage, in: Environment and Electrical Engineering (EEEIC), 2016 IEEE 16th International Conference on, IEEE, 2016, pp. 1-6.

[59] K. Chaudhari, A. Ukil, K. N. Kumar, U. Manandhar, S. K. Kollimalla, Hybrid optimization for economic deployment of ess in pv integrated ev charging station, IEEE Transactions on Industrial Informatics (2017).

[60] H. Zhao, A. Burke, An intelligent solar powered battery buffered ev charging station with solar electricity forecasting and ev charging load projection functions, in: Electric Vehicle Conference (IEVC), 2014 IEEE International, IEEE, 2014, pp. 1-7.

[61] W. Alharbi, K. Bhattacharya, Electric vehicle charging facility as a smart energy microhub, IEEE Transactions on Sustainable Energy (2016)

[62] M. S. Islam, N. Mithulananthan, K. Bhumkittipich, Feasibility of pv and battery energy storage based ev charging in different charging stations, in: Electrical Engineering/Electronics, Computer, Telecommunications and Information Technology (ECTI-CON), 2016 13th International Conference on, IEEE, 2016, pp. 1-6.

[63] G. C. Mouli, P. Bauer, M. Zeman, System design for a solar powered electric vehicle charging station for workplaces, Applied Energy 168 (2016) 434-443.

[64] X. Lu, N. Liu, Q. Chen, J. Zhang, Multi-objective optimal scheduling of a dc micro-grid consisted of pv system and ev 
charging station, in: Innovative Smart Grid Technologies-Asia (ISGT Asia), 2014 IEEE, IEEE, 2014, pp. 487-491.

[65] O. Lucon, D. Ürge-Vorsatz, A. Z. Ahmed, H. Akbari, P. Bertoldi, L. Cabeza, N. Eyre, A. Gadgil, L. Harvey, Y. Jiang, et al., Buildings (2014).

[66] C. Protopapadaki, D. Saelens, Heat pump and pv impact on residential low-voltage distribution grids as a function of building and district properties, Applied Energy 192 (2017) 268-281.

[67] D. Fischer, H. Madani, On heat pumps in smart grids: A review, Renewable and Sustainable Energy Reviews 70 (2017) $342-357$.

[68] Q. Zhang, T. Tezuka, K. N. Ishihara, B. C. Mclellan, Integration of pv power into future low-carbon smart electricity systems with ev and hp in kansai area, japan, Renewable Energy 44 (2012) 99-108.

[69] J. Van Roy, N. Leemput, F. Geth, J. Büscher, R. Salenbien, J. Driesen, Electric vehicle charging in an office building microgrid with distributed energy resources, IEEE Transactions on sustainable energy 5 (2014) 1389-1396.

[70] M. Honarmand, A. Zakariazadeh, S. Jadid, Self-scheduling of electric vehicles in an intelligent parking lot using stochastic optimization, Journal of the Franklin Institute 352 (2015) 449-467.

[71] T. Ackermann, Wind power in power systems, John Wiley \& Sons, 2005.

[72] J. J. Justo, F. Mwasilu, J. Lee, J.-W. Jung, Ac-microgrids versus dc-microgrids with distributed energy resources: A review, Renewable and Sustainable Energy Reviews 24 (2013) 387-405.

[73] E. Apostolaki-Iosifidou, P. Codani, W. Kempton, Measurement of power loss during electric vehicle charging and discharging, Energy 127 (2017) 730-742.

[74] M. S. ElNozahy, M. M. Salama, Uncertainty-based design of a bilayer distribution system for improved integration of phevs and pv arrays, IEEE Transactions on Sustainable Energy 6 (2015) 659-674.

[75] F. Kineavy, M. Duffy, Modelling and design of electric vehicle charging systems that include on-site renewable energy sources, in: Power Electronics for Distributed Generation Systems (PEDG), 2014 IEEE 5th International Symposium on, IEEE, 2014, pp. 1-8.

[76] S. I. Vagropoulos, L. Hadjidemetriou, A. G. Bakirtzis, E. Kyriakides, Assessment of electic losses minimization in commercial facilities through combined ev charging and pv generation operation (2014).

[77] A. B. Jaffe, R. N. Stavins, The energy-efficiency gap what does it mean?, Energy policy 22 (1994) 804-810.

[78] W. Saad, Z. Han, H. V. Poor, T. Basar, Game-theoretic methods for the smart grid: An overview of microgrid systems, demand-side management, and smart grid communications, IEEE Signal Processing Magazine 29 (2012) 86-105.

[79] L. M. Camarinha-Matos, Collaborative smart grids-a survey on trends, Renewable and Sustainable Energy Reviews 65 (2016) 283-294

[80] P. Ringler, D. Keles, W. Fichtner, Agent-based modelling and simulation of smart electricity grids and markets-a literature review, Renewable and Sustainable Energy Reviews 57 (2016) 205-215.

[81] I. Atzeni, L. G. Ordóñez, G. Scutari, D. P. Palomar, J. R. Fonollosa, Noncooperative and cooperative optimization of distributed energy generation and storage in the demand-side of the smart grid., IEEE Trans. Signal Processing 61 (2013) 2454-2472.

[82] R. Dai, M. Hu, D. Yang, Y. Chen, A collaborative operation decision model for distributed building clusters, Energy 84 (2015) 759-773.

[83] K. Binmore, A. Rubinstein, A. Wolinsky, The nash bargaining solution in economic modelling, The RAND Journal of Economics (1986) 176-188.

[84] A. Zakariazadeh, S. Jadid, P. Siano, Multi-objective scheduling of electric vehicles in smart distribution system, Energy Conversion and Management 79 (2014) 43-53.

[85] F. Zou, N. Liu, Q. Chen, Multi-party energy management for ev charging station cooperated with pv systems in smart grid, in: Innovative Smart Grid Technologies-Asia (ISGT ASIA), 2015 IEEE, IEEE, 2015, pp. 1-6.

[86] M. Kubli, M. Loock, R. Wüstenhagen, The flexible prosumer: Measuring the willingness to co-create distributed flexibility, Energy Policy 114 (2018) 540-548.

[87] N. Liu, M. Cheng, Effectiveness evaluation for a commercialized pv-assisted charging station, Sustainability 9 (2017) 323.

[88] R. L. G. Latimier, T. Kovaltchouk, H. B. Ahmed, B. Multon, Preliminary sizing of a collaborative system: Photovoltaic power plant and electric vehicle fleet, in: Ecological Vehicles and Renewable Energies (EVER), 2014 Ninth International Conference on, IEEE, 2014, pp. 1-9.

[89] Y. Kuang, M. Hu, R. Dai, D. Yang, A collaborative decision model for electric vehicle to building integration, Energy Procedia 105 (2017) 2077-2082.

[90] I. J. Pérez-Arriaga, Regulation of the power sector, Springer, 2014.

[91] C. Eid, J. R. Guillén, P. F. Marín, R. Hakvoort, The economic effect of electricity net-metering with solar pv: Consequences for network cost recovery, cross subsidies and policy objectives, Energy Policy 75 (2014) $244-254$.

[92] K. Knezović, M. Marinelli, A. Zecchino, P. B. Andersen, C. Traeholt, Supporting involvement of electric vehicles in distribution grids: Lowering the barriers for a proactive integration, Energy (2017).

[93] K. Mahmud, S. Morsalin, Y. Kafle, G. Town, Improved peak shaving in grid-connected domestic power systems combining photovoltaic generation, battery storage, and v2g-capable electric vehicle, in: Power System Technology (POWERCON), 2016 IEEE International Conference on, IEEE, 2016, pp. 1-4.

[94] J. P. E. Santo, R. Godina, E. M. Rodrigues, E. Pouresmaeil, J. P. Catalão, Ev charging effect on a distribution transformer supplying a factory with local pv generation, in: PowerTech, 2017 IEEE Manchester, IEEE, 2017, pp. 1-5.

[95] M. Gray, W. Morsi, On the impact of single-phase plug-in electric vehicles charging and rooftop solar photovoltaic on distribution transformer aging, Electric Power Systems Research 148 (2017) 202-209.

[96] K. D. McBee, Transformer aging due to high penetrations of pv, ev charging, and energy storage applications, in: Green 
Technologies Conference (GreenTech), 2017 Ninth Annual IEEE, IEEE, 2017, pp. 163-170.

[97] X.-L. Dang, M. Petit, P. Codani, Transformer operating conditions under introduction of pv and evs in an eco-district, in: Power \& Energy Society General Meeting, 2015 IEEE, IEEE, 2015, pp. 1-5.

[98] J. C. Lagares, J. R. Fernandez, M. B. Payan, J. M. R. Santos, Synergy of photovoltaic generators and electric vehicles in a low voltage distribution grid, in: PowerTech, 2011 IEEE Trondheim, IEEE, 2011, pp. 1-6.

[99] K. Knezović, M. Marinelli, R. Juul, P. B. Andersen, C. Træholt, F. Sossan, et al., Analysis of voltage support by electric vehicles and photovoltaic in a real danish low voltage network, in: Power Engineering Conference (UPEC), 2014 49th International Universities, IEEE, 2014, pp. 1-6.

[100] Z. Yang, B. Duan, M. Chen, Z. Zhu, A proactive operation strategy of electric vehicle charging-discharging in photovoltaic micro-grid, in: Innovative Smart Grid Technologies Conference (ISGT), 2016 IEEE Power \& Energy Society, IEEE, 2016, pp. $1-5$.

[101] O. Gandhi, W. Zhang, C. D. Rodríguez-Gallegos, D. Srinivasan, T. Reindl, Continuous optimization of reactive power from pv and ev in distribution system, in: Innovative Smart Grid Technologies-Asia (ISGT-Asia), 2016 IEEE, IEEE, 2016, pp. 281-287.

[102] H. Zhang, S. J. Moura, Z. Hu, W. Qi, Y. Song, Joint planning of pev fast-charging network and distributed pv generation, arXiv preprint arXiv:1702.07120 (2017).

[103] D. M. Tovilović, N. L. Rajaković, The simultaneous impact of photovoltaic systems and plug-in electric vehicles on the daily load and voltage profiles and the harmonic voltage distortions in urban distribution systems, Renewable Energy 76 (2015) 454-464.

[104] P. Denholm, M. O'Connell, G. Brinkman, J. Jorgenson, Overgeneration from solar energy in california: A field guide to the duck chart, National Renewable Energy Laboratory, Tech. Rep. NREL/TP-6A20-65023 (2015).

[105] A. Zecchino, K. Knezović, M. Marinelli, Identification of conflicts between transmission and distribution system operators when acquiring ancillary services from electric vehicles, in: 2017 IEEE PES Innovative Smart Grid Technologies Conference Europe, IEEE, 2017.

[106] S. P. Burger, M. Luke, Business models for distributed energy resources: A review and empirical analysis, Energy Policy 109 (2017) 230-248.

[107] N. Popiolek, F. Thais, Multi-criteria analysis of innovation policies in favour of solar mobility in france by 2030, Energy Policy 97 (2016) 202-219.

[108] M. Schreiber, M. E. Wainstein, P. Hochloff, R. Dargaville, Flexible electricity tariffs: Power and energy price signals designed for a smarter grid, Energy 93 (2015) 2568-2581.

[109] T. Kaschub, P. Jochem, W. Fichtner, Solar energy storage in german households: profitability, load changes and flexibility, Energy Policy 98 (2016) 520-532.

[110] I. J. Pérez-Arriaga, J. D. Jenkins, C. Batlle, A regulatory framework for an evolving electricity sector: Highlights of the mit utility of the future study, Economics of Energy \& Environmental Policy 6 (2017).

[111] S. Burger, J. P. Chaves-Ávila, C. Batlle, I. J. Pérez-Arriaga, The value of aggregators in electricity systems, MIT working paper (2016).

[112] O. Borne, K. Korte, Y. Perez, M. Petit, A. Purkus, Barriers to entry in frequency-regulation services markets: Review of the status quo and options for improvements, Renewable and Sustainable Energy Reviews 81 (2018) 605-614.

[113] G. R. C. Mouli, M. Leendertse, V. Prasanth, P. Bauer, S. Silvester, S. van de Geer, M. Zeman, Economic and co2 emission benefits of a solar powered electric vehicle charging station for workplaces in the netherlands, in: Transportation Electrification Conference and Expo (ITEC), 2016 IEEE, IEEE, 2016, pp. 1-7.

[114] M. Wolsink, The research agenda on social acceptance of distributed generation in smart grids: Renewable as common pool resources, Renewable and Sustainable Energy Reviews 16 (2012) 822-835. 
Interactions between electric mobility and photovoltaic generation: a review

Quentin HOARAU, Yannick PEREZ

Capturing industrial $\mathrm{CO}^{2}$ emissions in Spain: Infrastructures, costs and

N'2018-01 break-even prices

Olivier MASSOL, Stéphane TCHUNG-MING, Albert BANAL- ESTAÑOL

Measuring the Inventive Performance with Patent Data : an Application to Low Carbon Energy Technologies

N²017-09 Clément BONNET

Accessing the implementation of the market stability reserve $N^{\circ} 2017-08$ Corinne CHATON, Anna CRETI, Maria-Eugenia SANIN

Heat or power: how to increase the use of energy wood at the lowest costs?

Vincent BERTRAND, Sylvain CAURLA, Elodie LE CADRE, Philippe DELACOTE

A Theory of Gains from Trade in Multilaterally Linked ETSs

$N^{\circ} 2017-06$ Baran DODA, Simon QUEMIN, Luca TASCHINI

Demand-pull instruments and the development of wind power in Europe: A counter-factual analysis Marc BAUDRY, Clément BONNET

Co-firing coal with biomass under mandatory obligation for renewable electricity: Implication for the electricity mix

N'2017-04 Vincent BERTRAND

\section{Working Paper Publication Director : Philippe Delacote}

The views expressed in these documents by named authors are solely the responsibility of those authors. They assume full responsibility for any errors or omissions.

The Climate Economics Chair is a joint initiative by Paris-Dauphine University, CDC, TOTAL and EDF, under the aegis of the European Institute of Finance. 